\title{
Effect of Peptization on Densification and Phase-Transformation Behavior of Sol-Gel-Derived Nanostructured Titania
}

\author{
Krishnankutty-Nair P. Kumar," Jalajakumari Kumar, and Klaas Keizer \\ Laboratory for Inorganic Chemistry, Materials Science, and Catalysis, Faculty of Chemical Technology, \\ University of Twente, 7500 AE Enschede, The Netherlands
}

\begin{abstract}
Porosity reduction, packing, pore-size distribution, and anatase to rutile phase transformation behavior of nanostructured titania ceramics prepared from both peptized and unpeptized sols were studied and compared using XRD, DSC, and nitrogen-gas physisorption techniques. Precursor gels prepared from the peptized sol had a green density of about $70 \%$ after drying at $40^{\circ} \mathrm{C}$, whereas the samples prepared from the unpeptized sol had a green density of only $50 \%$. Samples prepared from the peptized sol showed higher sintering and phase transformation rates compared to the unpeptized sols.
\end{abstract}

\section{Introduction}

$\mathbf{N}$ ANOSTRUCTURED materials are currently receiving a lot of attention because of their interesting electrical, magnetic, optical, and mechanical properties. ${ }^{1-5}$ It has been shown in a previous publication ${ }^{5}$ that it is possible to produce nanostructured titania with near theoretical densities at temperature as low as $600^{\circ} \mathrm{C}$. There are two important differences between the procedure given in Ref. 5 and those reported earlier. ${ }^{6.7}$ In Ref. 5, the sintering was conducted during the anatase to rutile phase transformation, and the starting gel samples were prepared from a peptized sol. In this paper we report the importance of peptization in obtaining a precursor gel with maximum green density. Titania precursor gels were prepared from both peptized and unpeptized sols to compare the porosity reduction and anatase to rutile phase transformation behavior.

\section{Experimental Procedure}

\section{(1) Preparation of Anatase Sol}

It was reported earlier that it is possible to prepare particulate hydrosol of anatase by the hydrolysis of titanium isopropoxide. ${ }^{58}$ Figure 1 shows the different stages involved in the preparation of both peptized and unpeptized titania precursor sol. Titanium isopropoxide was hydrolyzed with water to get a thick, white precipitate of titanium oxyhydroxide. The precipitate was then washed to remove the excess alcohol present. After it was filtered and washed, the precipitate was redispersed in water containing nitric acid to get a $\mathrm{H}^{+}: \mathrm{Ti}^{4+}$ ratio of 0.5 . This dispersion was divided into two parts, and one part was directly poured into glass or polyethylene petri dishes and dried at $40^{\circ} \mathrm{C}$ and $60 \%$ relative humidity. The other part was peptized by heating at $80^{\circ} \mathrm{C}$ for $12 \mathrm{~h}$. This treatment produced a stabilized sol with a light-blue color. When the peptization conditions, i.e., temperature and time, were changed, a slight difference in the primary particle size occurred. When the peptization temperature was below $50^{\circ} \mathrm{C}$, it took a very long time before the milky

M. F, Yan-contributing editor dispersion changed to a light-blue sol. On the other hand, peptization at $90^{\circ} \mathrm{C}$ was much faster and we could get a "good" sol in only 1 to $2 \mathrm{~h}$. The unpeptized sol appeared white. To determine the effect of nitric acid on the unpeptized samples, a small portion of the washed precipitate was redispersed in pure water (without nitric acid). The peptized sol was later dried in the same manner as the unpeptized sol. During the peptization treatment, the aggregates were broken down and became an electrostatically stabilized sol in which the titania primary particles were positively charged due to the adsorption of protons. It was noted that the unpeptized sol without nitric acid produced exactly the same result as the sol containing nitric acid. A typical sample size was $20 \mathrm{~mm} \times 10 \mathrm{~mm} \times 0.1 \mathrm{~mm}$.

\section{(2) Calcination, Thermal Analysis, and XRD}

Both peptized and unpeptized samples were heated at a rate of $100^{\circ} \mathrm{C} / \mathrm{h}$ up to temperatures ranging from $300^{\circ}$ to $600^{\circ} \mathrm{C}$ for $8 \mathrm{~h}$, and then they were furnace cooled. Differential thermal analysis/differential scanning calorimetry (DTA/DSC) and thermal gravimetric analysis (TGA) measurements were performed (Stanton Redcroft, London, England, and Thermal Science System, Polymer Laboratories, Inc., Amherst, MA) with heating rates in the range of $5^{\circ} \mathrm{C} / \mathrm{min}$ to $20^{\circ} \mathrm{C} / \mathrm{min}$ in flowing air $(20 \mathrm{~mL} / \mathrm{min}$ ). All the thermal analyses were conducted in air using alumina sample cups with $\alpha$-alumina as the reference material. The sample weight was kept at $40 \pm 2 \mathrm{mg}$.

Samples calcined at several temperatures were subjected to X-ray diffractometry (XRD) measurements (Model PW 1710, Philips, Eindhoven, The Netherlands) with $\mathrm{Cu} K \alpha$ radiation. Because very accurate data were needed, only the step-scan technique was used. The step scans were performed with a step size of $0.015^{\circ} 2 \theta$; the time of counting at each step was $10 \mathrm{~s}$. The scanning range was from $23^{\circ}$ to $46^{\circ} 2 \theta$.

\section{(3) Physical Adsorption Measurements}

Nitrogen-gas physisorption measurements of all the samples were conducted at liquid-nitrogen temperature (Model ASAP 24000, Micromeritics Instrument Corp., Norcross, GA). All the samples, other than the one heated at $40^{\circ} \mathrm{C}$ (degassed at room temperature), were degassed at $110^{\circ} \mathrm{C}$ prior to the actual measurements. The pore-size distribution, from the desorption branch of the isotherm, was calculated following the method developed by Barrett, Joyner, and Halenda (BJH), assuming a cylindrical pore model.

\section{Results}

XRD of the titania precursor gels, dried at $40^{\circ} \mathrm{C}$ and $60 \%$ relative humidity, made from both peptized and unpeptized sols, essentially produced the same pattern. All the major peaks corresponded to the anatase phase of titania. ${ }^{5}$ The peaks were very broad and indicated the presence of very small, primary particles. The primary particle size was calculated from X-ray line-broadening analysis to be about $6 \mathrm{~nm}$. This value is in good agreement with our results from field emission-scanning electron microscopy (FE-SEM) studies. ${ }^{5}$ The only difference, even though very small, observed between the peptized and the 


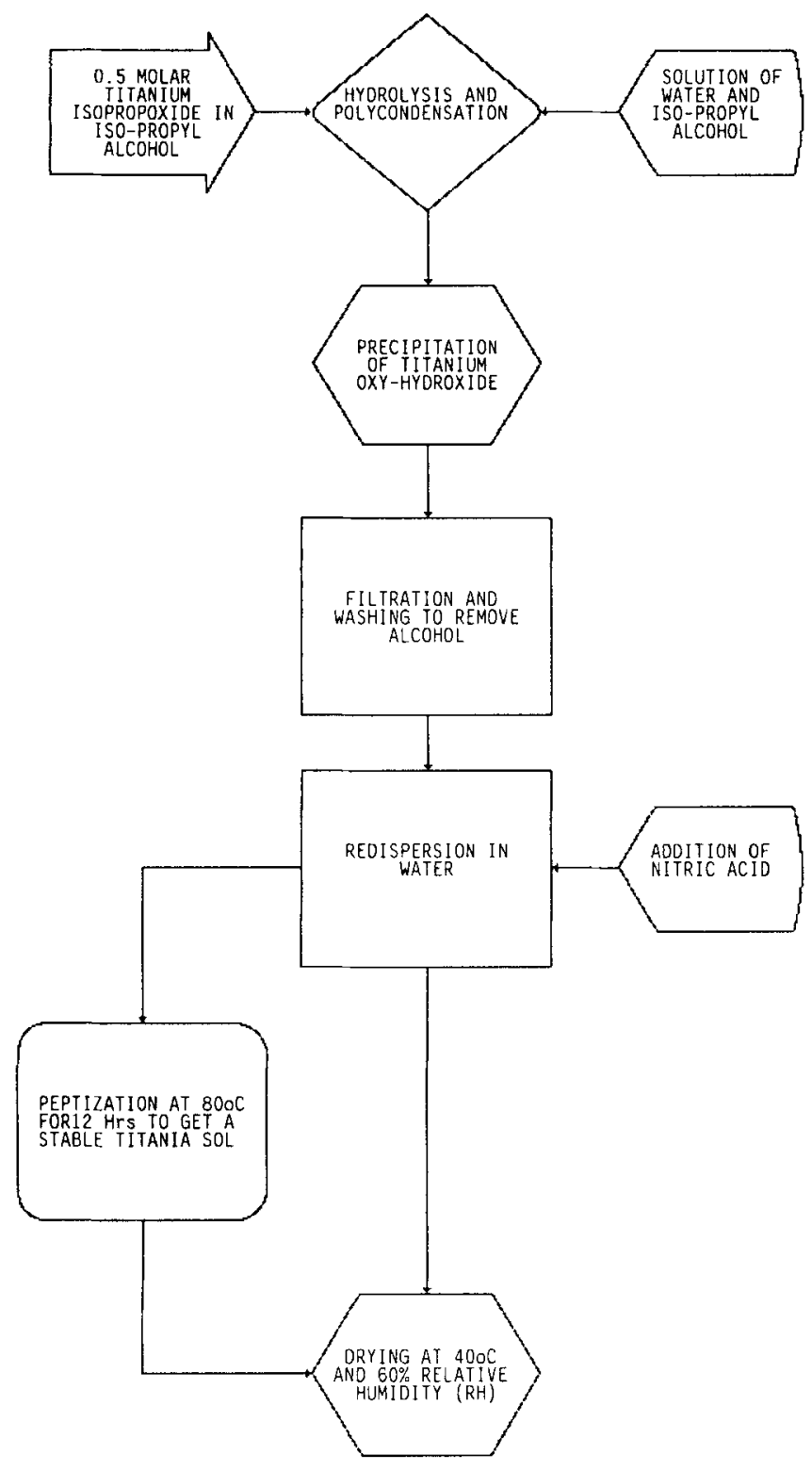

Fig. 1. Flow chart giving the different steps involved in the preparation of both peptized and unpeptized sols.

unpeptized samples was that the peptized sample was slightly more crystalline, which was indicated by the relatively narrower peaks. Most of the other reported gel-derived titania powders were amorphous in the as-prepared state.

Figures 2(a) to (c) and Figs. 3(a) to (c) give, respectively, the nitrogen-gas physisorption isotherms and the pore-size distribution of the samples prepared from both the peptized and the unpeptized sols heated at different temperatures. Figure 2(a) represents isotherms corresponding to the gels heated at $40^{\circ} \mathrm{C}$. The isotherm corresponding to the peptized sample is a typical type I with no hysteresis. This type of an isotherm is associated with microporous materials with uniform distribution of pores 2 $\mathrm{nm}$ or less in diameter. ${ }^{9.10}$ The absence of hysteresis (desorption branch follows the same path as the adsorption branch) clearly indicates the absence of pores larger than $2 \mathrm{~nm}$ in diameter (mesopores), or, in other words, no capillary condensation. ${ }^{9}$ The isotherm corresponding to the unpeptized gel is a typical example of a type-IV isotherm. Unlike the isotherm of the peptized gel, with no hysteresis, the unpeptized isotherm has two hysteresis loops, indicating a bimodal pore-size distribution. ${ }^{9}$ Figure 3(a) shows the pore-size distribution of the unpeptized gel calculated from the desorption branch of the isotherm. It is not possible to calculate the pore-size distribution of the peptized gel because the Kelvin equation is not applicable to microporous (pore diameter less than $2 \mathrm{~nm}$ ) systems. ${ }^{9}$ The porosities are about $30 \%$ and $50 \%$ for the peptized and the unpeptized gels, respectively. A type-I isotherm with no hysteresis and a low porosity clearly indicates the fact that packing and ordering in the peptized gel are much better than in the case of the unpeptized gel. Moreover, the unpeptized gel gives a bimodal poresize distribution (Fig. 3(a)) which points toward the fact that the precursor sol contains hard aggregates which are not completely broken down during drying. Hysteresis in a $P / P_{\circ}$ range of 0.5 and 0.7 may represent the intra-aggregate pores $(3.5 \mathrm{~nm})$ and hysteresis in the range of 0.9 and 1 may represent the interaggregate pores $\left(25\right.$ to $30 \mathrm{~nm}$ ). By $300^{\circ} \mathrm{C}$ (Fig. 2(b)), the isotherm that corresponds to the peptized sample represents a combination of types IV and I. There is a small hysteresis between the relative pressure 0.4 and 0.6 , indicating pore growth, and the isotherms are more similar to type IV. The pore-size distribution of the peptized sample is monomodal and relatively narrow compared with the bimodal distribution given by the unpeptized sample (Fig. 3(b)). At $450^{\circ} \mathrm{C}$ there is considerable pore growth for both unpeptized and peptized samples. This is indicated by the shift in the hysteresis loop to the right (Fig. 2(c)). The same trend is shown in the pore-size-distribution plots given in Fig. 3. At this temperature $\left(\sim 300^{\circ} \mathrm{F}\right)$ the unpeptized sample shows only one hysteresis loop, which corresponds to the smaller pore fraction, indicating the growth of a considerable portion of large pores beyond the level of detection. ${ }^{9}$ The pore size distribution is given in Fig. 3(c).

The surface area and average pore size with calcination temperature is summarized in Fig. 4. For the unpeptized sample, the surface area of the gel is about $300 \mathrm{~m}^{2} / \mathrm{g}$, and at $450^{\circ} \mathrm{C}$ it is about $70 \mathrm{~m}^{2} / \mathrm{g}$. The pores have grown from 3.6 to $7 \mathrm{~nm}$. For the peptized sample, the starting surface area is only $160 \mathrm{~m}^{2} / \mathrm{g}$, and at $450^{\circ} \mathrm{C}$ it is about $34 \mathrm{~m}^{2} / \mathrm{g}$. The pore size has increased from $<2$ to about $3.5 \mathrm{~nm}$. A comparison of pore growth and porosity reduction between samples prepared from both peptized and unpeptized sols is given in Table $\mathrm{I}$.

\section{Discussion}

There is a remarkable difference in the packing behavior of the peptized and unpeptized samples. During peptization, $\mathrm{H}^{+}$ ions from nitric acid are adsorbed onto the surface of the titania particles. Because all the particles have the same surface charge, the particles are repelled (double-layer repulsion) and a stable sol results with a minimum degree of aggregation. Unpeptized sols, whether or not they contained nitric acid, were dried immediately after redispersion in water. These unpeptized gels contain nonuniform, highly aggregated clusters of primary particles.

While they are drying, the particles in the sol are packed due to drying stresses. ${ }^{11}$ The origin of the drying stress is the capillary pull of the pore fluid and is directly proportional to the surface tension of the pore fluid and to the reciprocal of the pore radii." The pore fiuid is essentially the same in both peptized and unpeptized samples. Therefore, the magnitude of the drying stress is the same for both peptized and unpeptized samples, at least in the beginning of the drying stage. While they are drying, the particles are forced by the drying stresses to come together. Because of electrostatic repulsion, particles in the peptized sol are packed more uniformly compared to the unpeptized samples. In the unpeptized samples, because of the bimodal poresize distribution due to the presence of aggregates, the drying stress experienced by different regions in the sample are different. The particles within the aggregate tend to pack better compared to the regions in between the aggregates. This packing creates a nonuniform green microstructure. Moreover, the lack of electrostatic repulsion increases the chance of nonuniform packing, even within the aggregates.

Based on the above arguments, a qualitative model is presented below. In the case of samples prepared from a peptized 

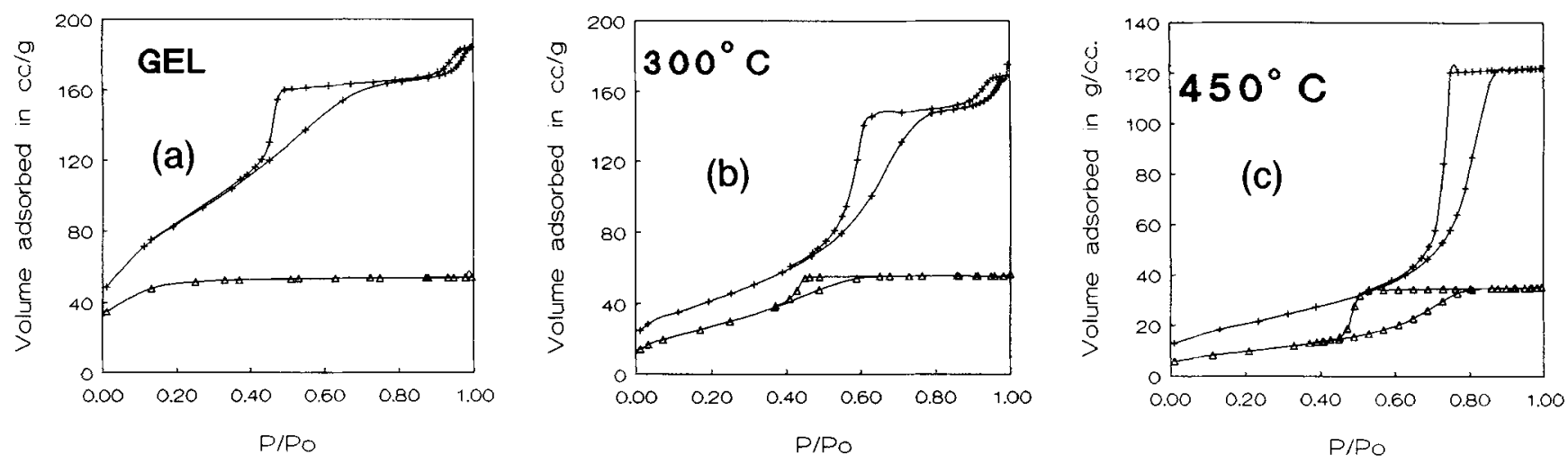

Fig. 2. Nitrogen-gas adsorption isotherms of samples prepared from both peptized ( $\Delta$ ) and unpeptized (+) sols heated at (a) $40^{\circ}$, (b) $300^{\circ}$, and (c) $450^{\circ} \mathrm{C}$ for $8 \mathrm{~h}$.

sol, there is perfect packing, indicated by the type-I isotherm, without a hysteresis loop (Fig. 2(a)). Ideally, the pores in the gel represent the interstitial voids of the close-packed primary particles. The porosity of the peptized gel is less than $30 \%$, which is very close to the ideal close-packed situation, where the porosity should be about $25 \%$. There are two types of pores present in the unpeptized gel, as shown in Fig. 3(a); they are intra-aggregate pores (represented by the hysteresis loop in the lower $P / P_{\mathrm{o}}$ range) and the inter-aggregate pores (hysteresis in the higher $P / P_{\mathrm{o}}$ range)

The peptized sol offers several advantages, with respect to attaining near theoretical density, over the conventional method of processing: ${ }^{5}$

(1) Particles are not exposed to the atmosphere, thus avoiding contamination during processing.

(2) A stabilized sol gives fewer aggregated particles than any other type of starting slurry.

(3) Particle packing and rearrangement during drying of the peptized sol is excellent, especially when the pore fluid is water, which has a high surface tension.

Barringer et al.$^{13}$ have noted that liquid-phase sintering and hot pressing, which can be used to achieve near theoretical density, essentially modify the initial microstructure in the same manner. In the first stage of liquid-phase sintering, the sharp edges of the particles are dissolved and the particles are rearranged by the surface tension of the liquid. ${ }^{13}$ This is the same as in the case of drying. In hot pressing, it is the applied pressure that causes the rearrangement to give a uniform close-packed structure. ${ }^{13}$

Springer and $\mathrm{Yan}^{7}$ and Barringer and Bowen pioneered the densification of titania ceramics. The main difference between the present work and, for example, Ref. 7 is the difference in the postprecipitation treatments. In the case of peptized titania, particles were not removed from the liquid medium (mainly water) until they were compacted by drying. However, in the present case, the samples were much smaller in size $(20 \mathrm{~mm} \times$ $10 \mathrm{~mm} \times 0.1 \mathrm{~mm})$. There was no calcination step before the final sintering; this avoids considerable particle growth. The starting particle size was about $6 \mathrm{~nm}$. The green compact had a porosity of about $30 \%$, and the phase was $100 \%$ anatase. Moreover, sintering was conducted during the anatase to rutile phase transformation. This has a positive effect on the densification kinetics. ${ }^{5}$

Differences in packing and coordination influence densification behavior and phase-transformation behavior; this, in turn, has an indirect influence on porosity reduction (densification). ${ }^{5}$ Lower coordination and level of packing leads to a lower sintering or porosity reduction rate. This behavior is expected from the basic sintering models. ${ }^{14}$ The DSC transformation temperature of the unpeptized sample is more than $125^{\circ} \mathrm{C}$ higher than that of the peptized samples. Figure 5 represents the XRD spectrum of samples heated at $450^{\circ} \mathrm{C}$ for $8 \mathrm{~h}$. The peaks marked $\mathrm{A}$ and $\mathrm{R}$ correspond to the anatase and rutile phases, respectively.
At $450^{\circ} \mathrm{C}$, more than $30 \%$ of the peptized sample has already transformed to rutile, whereas the unpeptized sample contains practically more than $98 \%$ anatase. Table II gives the kinetic parameters for the anatase to rutile phase transformation in peptized and unpeptized titania calculated from DSC data using the nonisothermal Avrami equation: ${ }^{15}$

$$
\frac{\frac{T_{\mathrm{p}}^{2}}{\phi} A}{\frac{E}{R}}=\exp \left(\frac{E}{R T_{\mathrm{p}}}\right)
$$

where $T_{\mathrm{p}}$ is the peak temperature (anatase to rutile phase transformation) obtained from DSC for a given heating rate $\phi, E$ the activation energy, $A$ the frequency factor, and $R$ the universal gas constant. There is a clear difference in the values of $E$ and $A$. The values of $E$ and $A$ for the unpeptized samples are similar to the values obtained for the anatase to rutile phase transformation in titania-alumina composites containing $3,6,9$, and 50 wt\% alumina. ${ }^{16}$ The only similarity between these materials and the unpeptized sample is in the effective coordination (and packing) of the particles, which is higher for the peptized samples.

The above results demonstrate the importance of the coordination of the primary particles in the phase transformation process. The number of nearest neighbors in actual physical contact can affect the phase transformation rate in two ways: It can affect either the nucleation rate or the growth rate or both. The critical nucleus size of rutile is expected to be larger ${ }^{16.17}$ than the primary crystallite size of the anatase. If this is true, then a lower coordination reduces the chance of a rutile nucleus reaching the critical size. After nucleation, the growth process is affected in the same manner as it is with the influence of coordination on sintering rate.

In the case of sintering conducted during the anatase to rutile phase transformation, the densification process is enhanced due to the so called Hedvall effect. ${ }^{18.19}$ Hedvall reported an increase in mass transport during solid-state transformations. ${ }^{18}$ In the case of peptized titania, there may be an additional enhancement in sintering due to the enhanced phase transformation rate by virtue of its higher packing and coordination (green density).

\section{Summary}

A well-packed initial microstructure is important for obtaining dense, nanostructured titania. The peptization step is very important to achieve this goal. If the final goal is to prepare precursors for nanostructured catalysts, the peptization step should be avoided. Unpeptized precursors show resistance to porosity reduction compared with the peptized samples because of lower packing and coordination. 

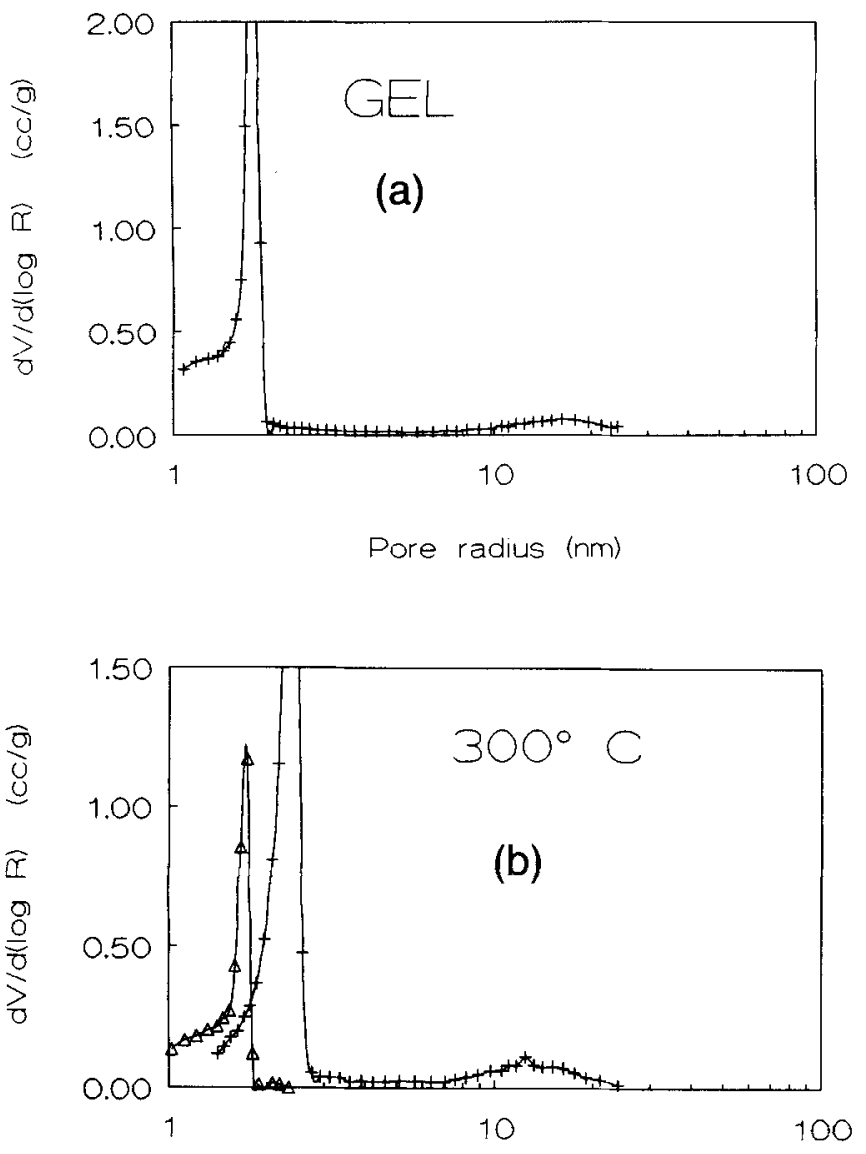

Pore radius (nm)

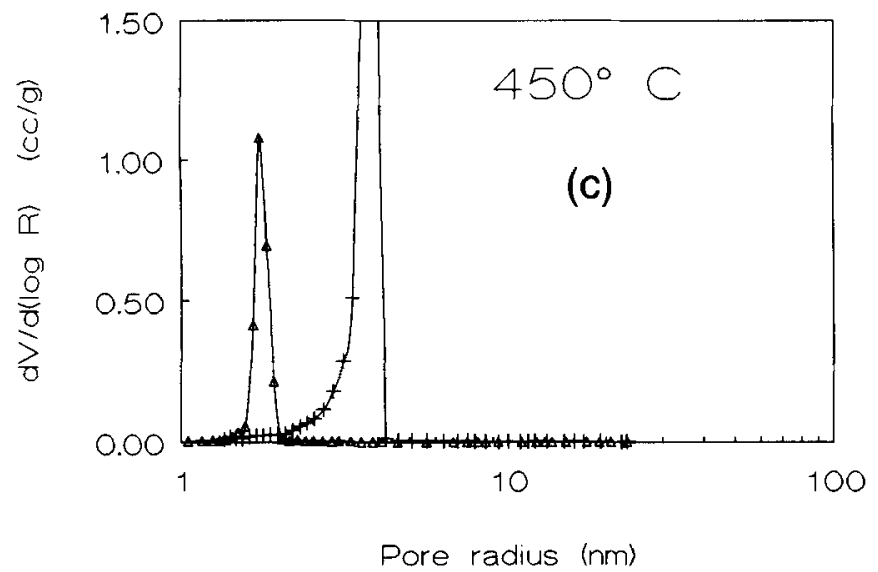

Fig. 3. Pore-size distribution of samples prepared from both peptized $(\Delta)$ and unpeptized $(+)$ sols heated at (a) $40^{\circ}$, (b) $300^{\circ}$, and (c) $450^{\circ} \mathrm{C}$ for $8 \mathrm{~h}$.

\section{References}

'H. Glieter, "Nanostructured Materials," Adv. Mater. (Weinheim, Fed. Repub. Ger.), 4, 474-81 (1992).

${ }^{2}$ H. Hahn, J. A. Eastman, and R. W. Siegel, "Processing of Nanophase Ceramics"; pp. 1115-22 in Ceramic Transactions, Vol. I, Ceramic Powder Science IIB. Edited by G. L. Messing and H. Hausner. American Ceramic Society, Westerville, $\mathrm{OH}, 1987$.

${ }^{3}$ A. J. Burggraaf, K. Keizer, and B. A. van Hassel, "Ceramic Nanostructured Materials, Membranes, and Composite Layers," Solid State Ionics, 32/33, 77182 (1989).

${ }^{4}$ M. M. R. Boutz, "Nanostructured Tetragonal Zirconia Ceramics"; Ph.D. Thesis. Faculty of Chemical Technology, University of Twente, Enschede, The Netherlands, 1993.

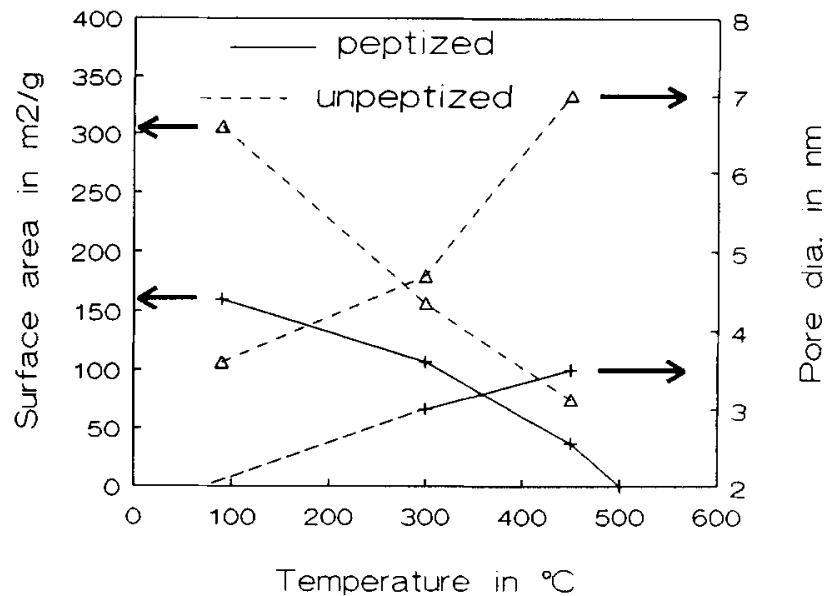

Fig. 4. Surface-area reduction and pore growth in samples prepared from both peptized (-) and unpeptized (---) sols, after calcination at different temperatures.

Table I. Porosity and Pore Diameter of Titania Samples Prepared from Both Peptized and Unpeptized Sols

\begin{tabular}{cccccc}
\hline \multirow{2}{*}{$\begin{array}{c}\text { Temperature } \\
\left({ }^{\circ} \mathrm{C}\right)\end{array}$} & \multicolumn{2}{c}{ Porosity $(\%)$} & & \multicolumn{2}{c}{ Pore diameter $(\mathrm{nm})$} \\
\cline { 2 - 3 } & Peptized & Unpeptized & & Peptized & Unpeptized \\
\hline 40 & 30 & 50 & & $<2$ & 3.5 \\
300 & 25 & 46 & 2.8 & 4.3 \\
450 & 15 & 40 & 3.5 & $>7$ \\
600 & 0 & 22 & & \\
\hline
\end{tabular}

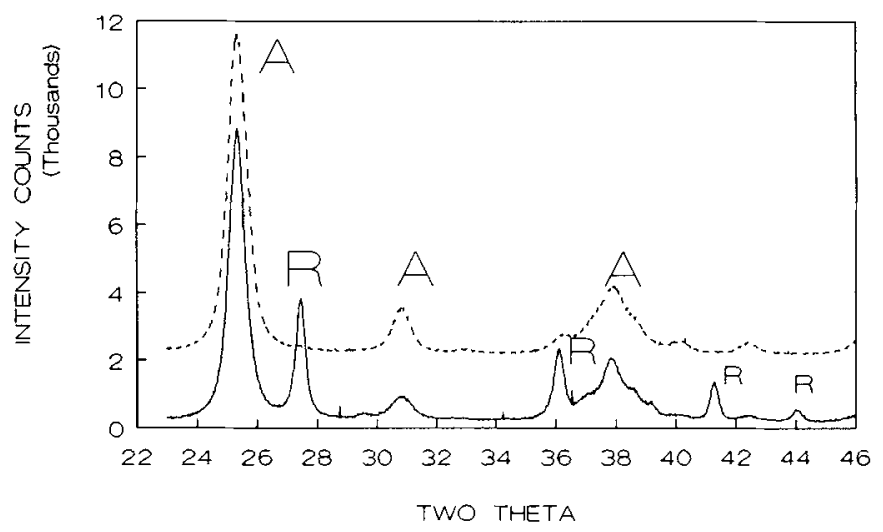

Fig. 5. XRD pattern of titania samples prepared from both peptized (-) and unpeptized (---) samples after calcination at $450^{\circ} \mathrm{C}$ for $8 \mathrm{~h}$.

Table II. Parameters from Nonisothermal Avrami Analysis

\begin{tabular}{|c|c|c|c|c|c|}
\hline Material & $\begin{array}{l}\text { Initial } \\
\text { porosity } \\
(\%)\end{array}$ & $\begin{array}{c}\text { DSC } \\
\text { transformation } \\
\text { temperature } \\
\left({ }^{\circ} \mathrm{C}\right)\end{array}$ & $\begin{array}{l}\text { Activation } \\
\text { energy, } \\
E(\mathrm{~kJ} / \mathrm{mol})\end{array}$ & $\begin{array}{c}\text { Frequency } \\
\text { factor, } \\
A\left(\times 10^{-7} \mathrm{~s}^{-1}\right)\end{array}$ & $\begin{array}{l}\text { Correlation } \\
\text { coefficient }\end{array}$ \\
\hline $\begin{array}{l}\text { Peptized } \\
\text { titania }\end{array}$ & 30 & 583 & 213 & 2.7 & 0.993 \\
\hline $\begin{array}{l}\text { Unpeptized } \\
\text { titania }\end{array}$ & 50 & 708 & 358 & 4.3 & 0.964 \\
\hline
\end{tabular}

${ }^{5}$ K.-N. P. Kumar, K. Keizer, A. J. Burggraaf, T. Okubo, H. Nagamoto, and S. Morooka, "Densification of Nanostructured Titania Assisted by a Phase Transformation," Nature (London), 358, 48-51 (1992).

${ }^{6}$ E. A. Barringer and H. K. Bowen, "Formation, Packing, and Sintering of Monodisperse $\mathrm{TiO}_{2}$ Powders," J. Am. Ceram. Soc., 65, C-199-C-201 (1982).

${ }^{7}$ L. Springer and M. F. Yan, "Sintering of TiO from Organometallic Precursors"; pp. 464-75 in Ultrastructure Processing of Ceramics, Glasses, and Composites, Edited by L. L. Hench and D. R. Ulrich. Wiley, New York, 1984. 
${ }^{8}$ (a) B. E. Yoldas, "Hydrolysis of Titanium Alkoxide and Effect of Hydrolytic Polycondensation Parameters," J. Mater. Sci., 21, 1087-92 (1986). (b) C. J. Brinker and G. W. Scherer, Sol-Gel Science; p. 46. Acadenic Press, New York, 1990. (c) V. T. Zaspalis, "Catalytically Active Ceramic Membranes: Synthesis, Properties, and Reactor Applications"; Ph.D. Thesis. University of 'Twente, Enschede, The Netherlands, 1990.

'(a) S. J. Gregg and K. S. W. Sing, Adsorprion, Surface Area, and Porosity, 2nd ed.: pp. 25, 195. Academic Press, London, U.K., (1982). (b) K. S. W. Sing, D. H. Everett, R. A. W. Haul, L. Moscou, R. A. Pierotti, J. Rouquerol, and T. Siemieniewska, "Reporting Physisorption Data for Gas/Solid Systems-With Special Reference to the Determination of Surface Area and Porosity," Pure Appl. Chem., 57 [4] 603-19 (1985).

"J. H. de Boer, "The Shapes of Capillaries"; pp. 68-94 in The Structure and Properties of Porous Materials. Edited by D. H. Everett and F. S. Stone. Butterworth, London, U.K., 1958.

"G. W. Scherer, "Theory of Drying," J. Am. Ceram. Soc, 73, 3-14 (1990).

${ }^{12}$ 1. A. Aksay and C. H. Schilling, "Colloidal Filtration Route to Uniform Microstructures"; see Ref, 7, pp. 439-47.

${ }^{13}$ E. A. Barringer, N. Jubb, B. Fegley, R. L. Pober, and H. K. Bowen, "Processing Monosized Powders"; see Ref. 7, pp. 315-33.
${ }^{34}$ E. G. Liniger and R. Raj, "Spacial Variations in the Sintering Rate of Ordered and Disordered Particle Structures," J. Am. Ceram. Soc., 71 [9] C-408C-410(1988)

${ }^{15}$ N. P. Bansal, R. H. Doremus, A. J. Bruce, and C. T. Moynhan, "Reply to "Comment on "Kinetics of Crystallization of $\mathrm{ZrF}_{4}-\mathrm{BaF}_{3}-\mathrm{LaF}_{3}$ Glass by Differential Scanning Calorimetry," "J.Am. Ceram. Soc., 66 [11] C-218 (1983).

${ }^{16}$ (a) K.-N. P. Kumar, K. Keizer, and A. J. Burggraaf, "Textural Stability of Titania-Alumina Composite Membranes," J. Mater. Chem., 3, 917-22 (1993). (b) K.-N. P. Kumar, "Nanostructured Ceramic Membranes"; Ph.D. Thesis. Faculty of Chemical Technology, University of Twente, Enschede, The Netherlands, 1993.

${ }^{17}$ M. J. Mayo, "Superplastisity of Nanostructured Ceramics"; Presented at NATO-ASI Meeting on Mechanical Properties and Behavior of Materials Having Ultrafine Microstructures, June 29-July 10, 1992, Vimeiro, Portugal.

${ }^{18} \mathrm{~J}$. A. Hedvall, Reaktionsfahiskeit Fester Sioffe (Reactivity of Solids). Vellang von Johann Ambrosius Barth, Leipzig, Germany, 1938.

${ }^{19} \mathrm{~W}$. D. Kingery, H. K. Bowen, and D. R. Uhlmann, Introduction to Ceramics, 2nd ed.; p. 425. Wiley, New York, 1976. 